\title{
Formación Pedagógica del Docente Universitario
}

\author{
CPC Emesto Polar Falcón \\ Magister en Educación
}

\section{PROLOGO}

Se inician estas reflexiones en torno a la formación pedagógica del docente universitario considerando el concepto de educación y sus fines, las implicancias éticas derivadas de una determinada conceptualización de la educación, los fines de la universidad, las tareas del trabajo universitario y la razón de ser docente, a los efectos de entender con claridad los enunciados del presente trabajo.

Se puede considerar que la educación consiste en el mejoramiento, en el perfeccionamiento intencional y en el crecimiento integral de la persona mediante la ayuda del educador; educar es personalizar; la persona da unidad al proceso educativo.

Para todo docente universitario, que pretenda ser docenteeducador, hay exigencias necesarias sin las cuales no habrá educación eficaz. Dichas exigencias, pueden resumirse en la consideración de dos factores:

A. La personalidad del docente-educador

El docente es un guía. Y para lograrlo debe tener o conseguir cualidades que definan lo que se ha dado en llamar "la personalidad del educador". Así se hace imprescindible esperar del docente universitario:

1. Aptitudes cognoscitivas

2. Aptitudes psicológicas

3. Aptitudes pedagógicas

4. Formación moral

\section{B. La técnica del docente-edu-} cador

Lograr una acción educativa eficaz, exige una personalidad bien formada, pero también exige un medio a través del cual pueda comunicarse y comunicar. Por lo tanto, el docente-educador debe conocer teóricamente y prácticamente los medios, los procedimientos, las formas que pueden garantizar a su enseñanza un máximo de eficiencia. Para lograr la formación pedagógica, será necesario que reciba cursos que podrán comprender fundamentalmente:

- Principios de pedagogía

- Principios de didáctica general

- Principios de didáctica especial de la propia asignatura

Todos estos conocimientos técnicos, deberían estar integrados por un período de prácticas supervisadas. Todo quehacer, incuído el educativo, tiene sus métodos específicos para alcanzar los fines. En consecuencia, el estudio de los métodos educativos es un aspecto clave en la formación pedagógica básica del docente universitario.

Todas las profesiones contemporáneas, también la del educador, evoluciona a pasos acelerados, y por consiguiente, requiere una actualización permanente. No basta con una formación inicial. Es preciso empeñarse en su perfeccionamiento permanente. El profesional de la educación se está haciendo continuamente.

La formación permanente puede entenderse como un proceso de cambio personal y situado en una realidad concreta; así como también puede verse como un proceso de identificación. El docente universitario, debe proyectarse y buscar una imagen de sí, en relación con los demás o con lo demás. Asimismo, esta formación permanente es un proceso de compromiso personaldel docente universitario, por cuanto se liga, se compromete personalmente consigo mismo en la tarea de su continua formación o mejoramiento. 
El docente universitario, tiene dos formas fundamentales de desarrollar: el perfeccionamiento $\mathrm{y}$ el autoperfeccionamiento. Los programas intensivos de perfeccionamiento de profesores, pueden ubicarse en un momento cualquiera de la carrera docenteprofesional y es preciso tener una experiencia mínima que preste significación a los problemas abordados dentro del programa, con lo cual el aprendizaje se hace más firme a diferencia del que se da en los programas de formación, en los que no se apoya el aprendizaje teórico con una experiencia real. Los objetivos para el perfeccionamiento de docentes universitarios requieren de la utilización de la metodología participativa, por la cual, cada uno de los participantes del programa pasan de una postura de contemplar a otra de tomar parte en la situación de aprendizaje, hasta llegar a ser parte de esa misma situación, las tareas de perfeccionamiento con base en la experiencia personal de quienes componen el grupo de estudio, llevan a redescubrir los principios a partir de la realidad y a mejorar por supuesto, el aprendizaje.

De la necesidad de autoperfeccionamiento se deriva la exigencia de investigación del docente universitario, que debe ser activa, tomando como fuente de problema, aquellos que se derivan de su propia experiencia.

\footnotetext{
Ahora bien, educar es en todo caso, una auténtica vocación. La vocación personal determina las principales disposiciones de ideales hacia lo que actúa. La vocación exige preparación. Nadie enseña lo que no sabe, ni ejerce influjo en la formación de las virtudes sin el ejemplo. Es necesario ser algo para poder dar. La vocación conlleva la necesidad de tener una formación inicial para el
}

ejercicio de la docencia universitaria y de mantener una continuidad basada en la formación pedagógica.

\section{EXIGENCIAS NECESA-} RIAS PARA EL EJERCICIO DE LA DOCENCIA UNIVERSITARIA

Los profesionales universitarios que quieren dedicarse o se dedican a la labor docente, deben ser conscientes de que han dejado de ser transmisores deconocimientos y que han pasado a ser verdaderos educadores. La universidad no es un lugar en el que transmiten conocimientos, donde sólo se desarrollan inteligencias, sino que es un lugar donde los alumnos pueden desarrollar su personalidad.

Esto ha de ser posible, por cuanto la universidad debe de disponer de docente preparados y de medios adecuados para favorecer este desarrollo, es decir, la creación de un ambiente que permita la formación de personas que sepan afrontar el porvenir.

Ahora bien, si se pretende formar personas realmente educadas, más que transmitir conocimientos, el docente universitario, necesita desarrollaractitudes y aptitudes. En realidad, el docente universitario, en su misión de educador, necesita contar con cualidades mucho mayores que las que se han dado hasta ahora; por eso el nuevo educador debe saberque másque por lo quedice o hace en el aula, educa por lo que es, es decir, por su personalidad. Debe tener una clara conciencia de su misión, por cuanto, su función es esencialmente educativa y responsabilizarse deque la educación sea una realidad en los alumnos. Ser profesor es ser educador $y$ por lo tanto orientador de los alumnos.

Se han efectuado diversas in- vestigaciones en las universidades, para precisar las cualidades de los docentes universitarios, llegándose a análogas conclusiones, de que a un docente universitario se exige:

- Competencia en su materia

- Buena cultura general

- Aptitudes y destrezas psicopedagógicas

- Experto en técnicas de trabajo intelectual

- Buen conocedor de los problemas universitarios

- Aptitud de aceptación del alumno

- Guía de Valores

Si se toma el término de docente universitario, en su acepción más amplia, como aquel que en cualquier nivel de enseñanza, forma a los jóvenes alumnos a través de las fuerzas plasmadoras de la autoridad y el conocimiento, se puede en sintesis afirmar que todo docente universitario que pretende el ejercicio de la enseñanza, debe considerar los dos siguientes factores:

A. La personalidad del docente-educador

Eldocente universitario, como persona educadora, es un ser que debe ponerseal servicio del alumno, para conducirlo a una meta de perfección personal. Debe enriquecerse para enriquecer, mejorarse para mejorar y adquirir autonomía para conducir a otros a la autonomía. Por consiguiente, el docente universitario es un guia. Y para lograrlo debe tenero conseguir tener cualidades que definan lo que se ha dado en llamar "la personalidad del docente-educador". Se espera que el docente universitario tenga:

1. Aptitudes cognoscitivas

a. Cultura general: "... La Historia, los Hombres, las Ideas. El empleo consciente de mayúsculas significa que se está pensando aquí en los sistemas políticos, en 


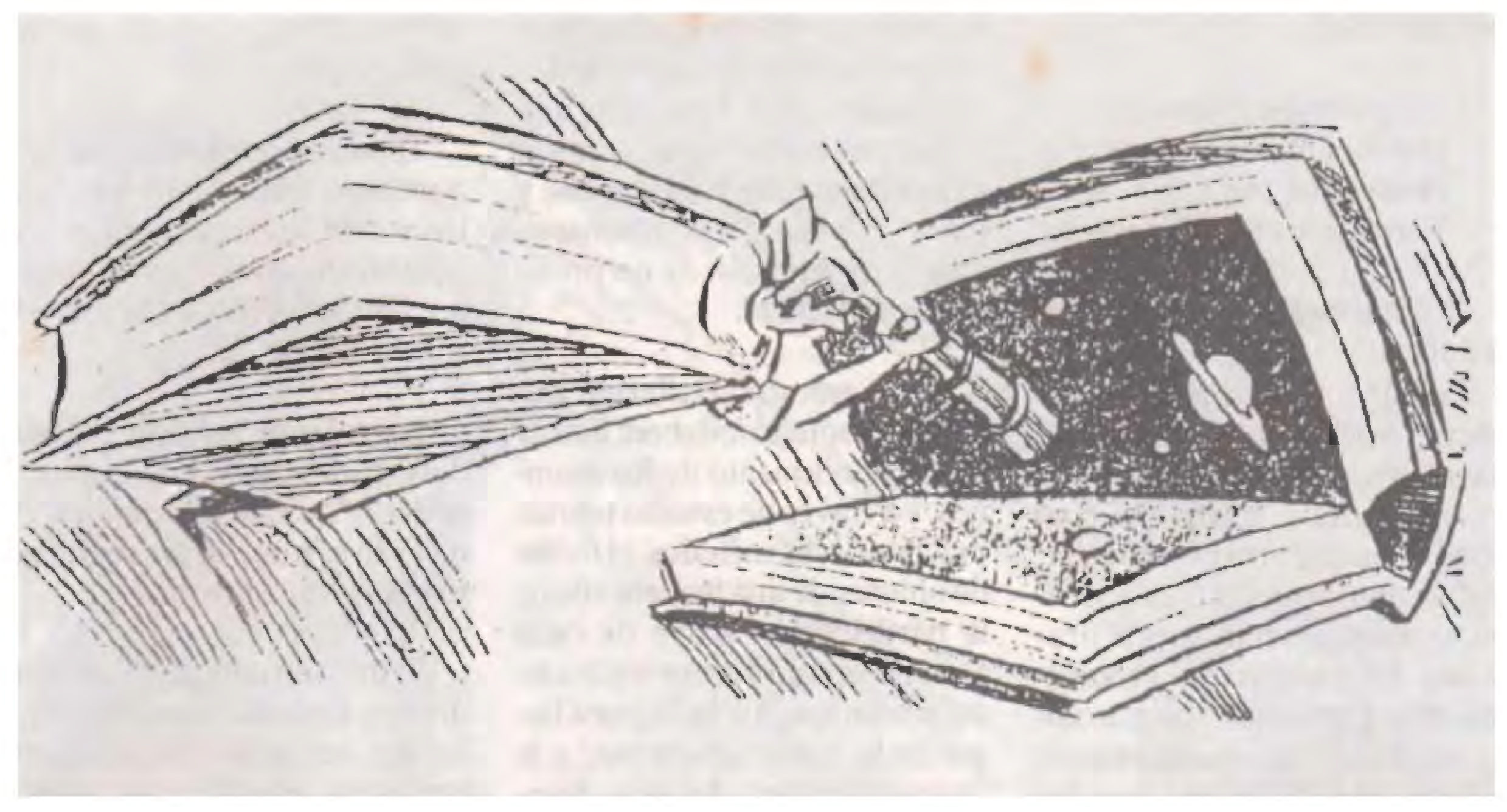

las mentalidades, en la psicología de los individuos y de los pueblos..."

b. Cultura especializada: es decir, poseer en forma amplia, una variedad y riqueza de conocimientos en el área concreta del saber correspondiente a la especialización. Se exige además, una penetración sintética en la propia materia en función del nivel universitario de alumnos a los cuales se ha de formar.

\section{Aptitudes psicológicas}

Lo cual significa conocimiento del alumno desde el punto de vista fisiológico, psicológico, moral, social y religioso. Un conocimiento que no debe ser solamente general, sino también individual. El docente universitario debe estar al día, no sólo en lo que hace a la materia que explica, sino que, si desea ser eficaz debe conocer aspectos básicos de psicología de los educandos, las características de los grupos, técnicas didácticas, etc. Esto se debe a la trascendencia que tiene el trabajo docente en el campo social.

El conocimiento de las con- ductas del educando (entendiendo que la conducta involucra actividades relacionadas con el área de la mente, del cuerpo y del medio circundante, tendientes a reducir tensiones y realizar posibilidades), permitirán al docente universitario estructurar su trabajo de manera que posibilite la modificación de las pautas de conducta en procura del desarrollo integral del alumno.

\section{Aptitudes pedagógicas}

Las aptitudes psicológicas y pedagógicas, son las que hacen al simple profesor universitario, un educador, capaz de comunicar y presentar en forma conveniente, organizada, clara y personalizada los contenidos del aprendizaje.Supone capacidades innatas, que pueden perfeccionarse en gran medida mediante la pedagogía y la didáctica, y un ejercicio inteligente de la docencia.

¿Cómo resultan operativas estas aptitudes? Resultan operativas, después de haberse fijado en la humanidad del docente universitario, que se desarrolla mediante el ejercicio de las virtudes humanas, que hacen fecunda su labor: prudencia, justicia, fortaleza, templanza, etc. Por lo tanto, para que el docente universitario pueda lograr ser un guía, un orientador eficaz, debe enriquecer su personalidad.

\section{Formación moral}

En todos los países existe una profunda preocupación por formar mejores docentes universitarios, para lograr una generación de mejores graduados.

Si la educación es un proceso interior personal, será completa, cuando no se quede solamente en la adquisición de conocimientos, ni siquiera de aptitudes, sino que llega al mundo de los valores, principalmente de los valores morales. Por lo tanto, la formación moral del profesor o docente universitario no se improvisa, ni tampoco puede dejarse librada a la buena voluntad. Esa formación del docente-educador, no puede limitarse a suministrar una formación cultural, a proveerlo de técnicas didácticas, como útiles del oficio. Para que la formación pedagógica profesional universitaria sea operativa y 
eficaz, debe estarinmersa en una personalidad:

- Integralmente formada

- Humanamente auténtica

- Eticamente comprometida

- Vocacionalmente orientada

\section{B. La técnica del docente-edu- cador}

Lograr una acción educativa eficaz, exige una personalidad bien formada, pero también exige un medio a través del cual pueda comunicarse y comunicar. Eldocente universitario, debe conocer teóricamente y prácticamente los medios, los procedimientos, las formas que puedan garantizar a su enseñanza un máximo de eficiencia. Para lograr la formación pedagógica requiere que pueda asistir a cursos que podrá comprender fundamentalmente:

- Principios de pedagogía

- Principios de didáctica general

- Principios de didáctica especial de la propia asignatura

Estos conocimientos técnicos deberían ser integrados por un período de prácticas supervisadas. A continuación se recogen las siguientes reflexiones:

"Personas de formación universitaria que deseasen dedicarse a la enseñanza en las universidades, tendrían que hacer un curso que comprenda materias pedagógicas (psicología, sociología, filosofía de la educación y didáctica general y especial) más prácticas de enseñanzas.

"Sería imperdonable dejarque el docente universitario se formase a través de los años de ejercicio de la docencia, por el proceso de "ensayo y error", pues está en juego el futuro de seres humanos".

"Por eso la universidad a más de las clases, trabajos, colabora- ción con el titular de la cátedra, durante un determinado número de años, deberá exigir a todos los candidatos a la carrera universitaria, cursar algunas materias pedagógicas y didácticas; y hacer práctica de la enseñanza bajo la supervisión de un profesor de didáctica".

El docente universitario, celoso de su profesión, deberá buscar en el conocimiento de los alumnos, y a través de estudio teórico práctico de los métodos, el modo de obtener de una manera eficaz, la participación activa de cada alumno en el proceso instructivo-formativo. Así se logrará llegar de la "heteroeducación" a la "autoeducación". En este desarrollo está implícita la idea de que la formación profesional será tanto como la adquisición de conocimientos y destrezas en orden a la plasmación de una personalidad especialmente apta para el ejercicio de una actividad socialmente útil llamada profesión.

La formación se debe distinguir de la enseñanza; la formación implica completar la personalidad del hombre para el trabajo, para lo cual no sólo necesita destrezas y aprendizajes técnicos, sino formación social, humana y ante todo, formación moral.

\section{EL METODO PEDAGO- GICO EN LA FORMACION DELDOCENTEUNIVERSITA- RIO}

La acción educativa, al igual que muchas otras actividades humanas, posee técnicas, recursos y métodos para alcanzar los finesque se propone. Por supuesto que en toda función educativa hay un factor personal insustituible, que depende de la singularidad del docente universitario y que la técnica no puede resolver por sí misma. Pero es evidente que el estudio de los métodos o técnicas pedagógicas es ineludible para una buena acción educativa.

Toda actividad humana, todo quehacer, toda forma de obrar, tiene sus métodos específicos para alcanzar los fines. El quehacer educativo no escapa a esta consideración.

La palabra método procede del griego "methodos", que quiere decir "caminos o senderos". El método es pues, el procedimiento para alcanzar algo.

El método educativo, es la reunión y síntesis de medidas educativas, que se basan sobre conocimientos psicológicos, claros, seguros y completos; y sobre lógicas; y que realizadas con habilidad personal, alcanzan sin rodeo el fin previamentefijado. Esta definición es buena y completa, por cuanto contiene los siguientes caracteres esenciales del método:

1. Carácter lógico: Responde a las leyes del pensamiento.

2. Carácter psicológico: Se adecúa a los educandos

3. Carácter económico: Produce efectos importantes con poco esfuerzo.

4. Carácter ético-estético: Se ejecuta con habilidad de artista

5. Carácter personal: Acorde con la personalidad del educador.

Ahora bien, ¿Cuál es el verdadero valor del método pedagógico?. Frecuentemente se escucha que más es un buen docente universitario que un buen método; y que, seacual fuere el método usado por este docente, los resultados son necesariamente buenos. Esto que puede ser cierto, no quita sentido al método. Cuando el docente universitario haya adquirido los principios generales dealgún método, deberá preocuparse por buscar los métodos que 


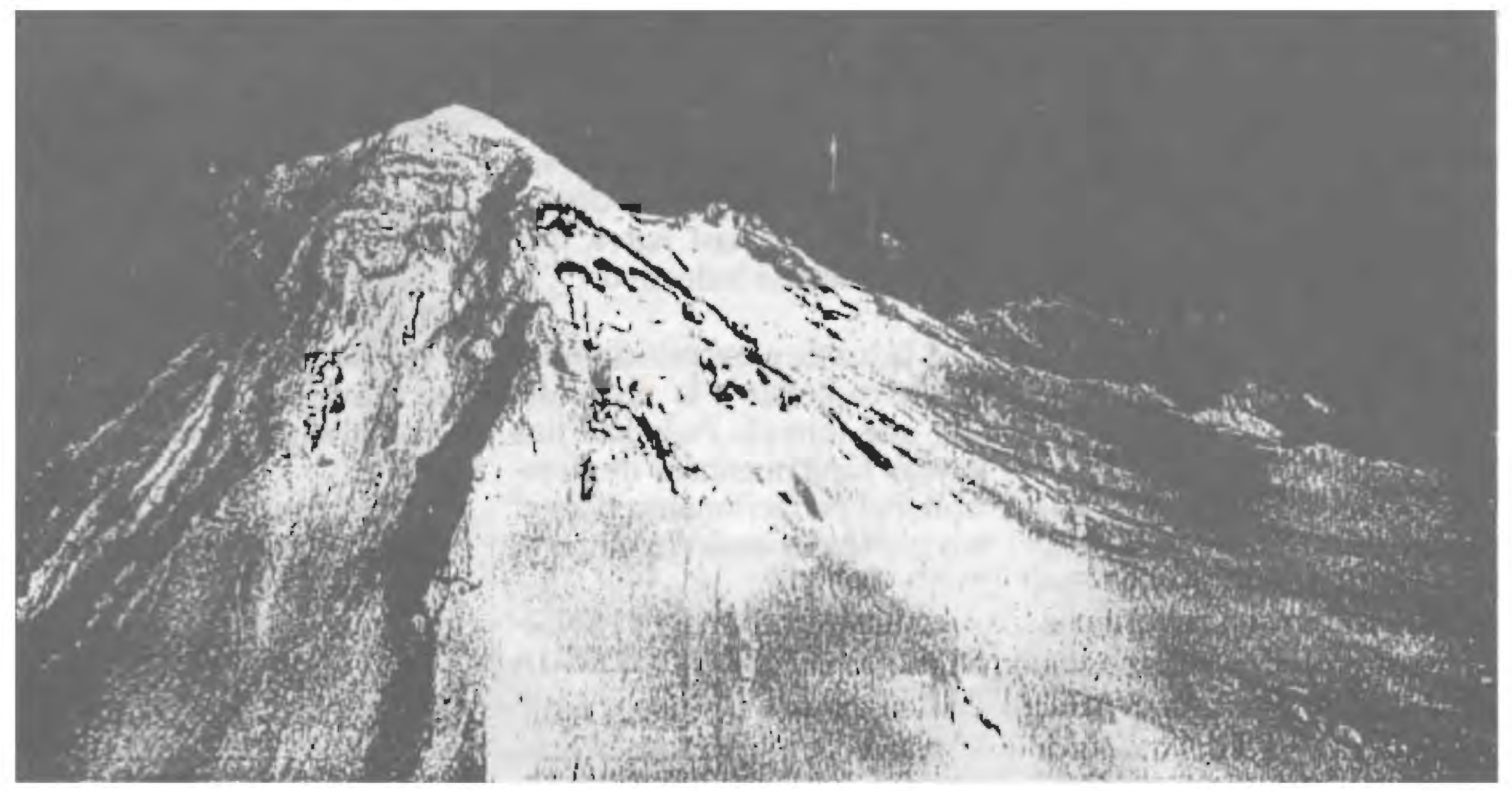

mejor se adapten a su personalidad para aplicarlos.

En base a lo expresado, se obtienen las siguientes conclusiones:

1. Si no hay método, no se cumplen las finalidades de la universidad: instrucción, aprendizaje y educación.

2. Un método existe siempre; se trata de que sea el mejor posible; sólo así los contenidos pueden ser transmitidos eficazmente y se puede lograr una mayor rentabilidad de la inversión educativa.

3. Si los métodos no son adecuados, pueden impedir la transmisión de los contenidos; en consecuencia, es falso camino descuidar la atención de los métodos para dedicarse a los contenidos.

4. Hay que recordar que una gran parte del qué de una enseñanza (contenidos), depende de cómo se transmite (métodos).

Si el método pedagógico es la manera de dirigir, guiar y estimular a los alumnos en el proceso de aprendizaje. Un punto clave en la formación pedagógica del docente universitario es su estudio.

III. LA FORMACION PERMANENTE DEL DOCENTE UNIVERSITARIO

Todas las profesiones contemporáneas, también la del educador, evolucionan a pasos acelerados y requiere de una actualización permanente. No basta con una formación inicial. Es preciso empeñarse en su perfeccionamiento. Hacerse docente universitario, tiene un poco de profesar, en el sentido de "tomar estado" o adquirir un carácter impreso de una vez para siempre. El profesional de la educación se está haciendo continuamente. Necesita de una formación pedagógica inicial y un constante perfeccionamiento.

La formación permanente, puede entenderse como:

1. Un proceso para el cambio, para un cambio personal y situado en una realidad concreta.
Aumentar la cantidad de información no constituye perfeccionamiento propiamentedicho. Así por ejemplo, el estudio de las técnicas didácticas no sería perfeccionamiento si no se basara en el reconocimiento de los recursos personales para asimilarlos $y$ ponerlos en práctica. Es necesario que a partir de lo recibido se produzca una formación interior, es decir, un mejoramiento de la persona.

2. Puede verse el proceso de formación permanente como un proceso de identificación. El docente universitario proyecta y busca una imagen de sí, en relación con los demás.

3. La formación permanente es un proceso de compromiso personal. El docente universitario se liga, se implica, se compromete personalmenteconsigo mismo en la tarea de su continua formación o mejoramiento.

Como exigencia de la necesidad de mejora, de evitar la posible rutina y de los cambios operados en la sociedad, surge 
con una serie de actividades. El procesode formación permanente del docente universitario, que tomando como meta el facilitarel cambio, conlleva a identificar sus propias posibilidades y limitaciones. Es decir, a la identificación de sí mismo y que deriva en un compromiso con su propia actividad profesional. Ahora bien, surge una pregunta clave: ¿De qué forma se puede realizar el perfeccionamiento?

Para poder contestar a esta pregunta, antes hay que responder a esta otra: ¿Cuáles son los principios básicos que se requieren para realizar el perfeccionamiento?

Al respecto, puede considerarse que estos principios deberán ser los siguientes:

1. Crear un ambiente emocional que contribuya a la realización de un mejor proceso de aprendizaje.

2. Aldiseñar los cursos de perfeccionamiento se debe tener en cuenta la real problemática de los participantes.

3. Deberá facilitarse el procesodinámicode comunicación con otros docentes universitarios situados al mismo nivel profesional, para un intercambio de experiencias.

4. Deberá desarrollarse los cursosde perfeccionamiento dentro de un espíritu de libertad. Hay que ayudar al docente universitario a crecer, considerándolo como verdadero participante $o$ actor $y$ no como simple asistente o espectador.

5. Si se quiere que el docente universitario se implique en su tarea, es necesario orientar el proceso de perfeccionamiento por medio de la "metodología participativa".
6. Si se quiere provocar un aprendizaje eficaz, se debe situar al docente universitario en contacto con la realidad.

7. Si se quiere alcanzar un aprendizaje a través del descubrimiento personal habrá que usar un método inductivo.

A la luz de estos principios se puede contestar a la pregunta: ¿De qué forma?. Pues hay dos formas fundamentales de desarrollar el perfeccionamiento y el autoperfeccionamiento que son:

A. PROGRAMAS INTENSIVOS CON METODOLOGIA PARTICIPATIVA

Los programas intensivos de perfeccionamiento de docentes universitarios, pueden ubicarse en un momento cualquiera de la carrera profesional. Se hace preciso tener una experiencia mínima que preste significación a los problemas abordados dentro del programa de estudios, con lo cual el aprendizaje se hace más firme a diferencia del que se da en los programas de formación, en lo que no se apoya en aprendizaje teórico con una experiencia real.

Los objetivos de los programas intensivos de perfeccionamiento son:

1. Comparación tendiente a efectuar las correcciones que fueran necesarias, entre los enfoques educativos personales deldocente universitario, con los enfoques educativos propuestos en los programados intensivos de perfeccionamiento, para una mejor educación del estudiante.

2. Conocer y experimentar las técnicas de trabajo en la universidad, en especial las de metodología participativa.

3. Prácticas de trabajo en equipo con docentes de la misma Facultad y de otras instituciones de la profesión, con el objeto de intercambiar experiencias.

4. Desarrollar una actitud de reflexión sobre uno mismo, que conlleve a la identificación del propio estilo personal.

5. Desarrollar un actitud de reflexión que lleve a considerar la propia tarea educativa como una actividad moral y por ende, personal e intencional.

6. Desarrollar una actitud de preocupación por el perfeccionamiento permanente.

7. Lograr una actitud de compromiso personal, con las exigencias propias de la tarea educativa.

8. Lograr una actitud de contribuir a la renovación educativa de la Facultad en la cual realiza su tarea, en la medida de sus propias posibilidades.

Los objetivos para el perfeccionamiento de docentes universitarios, requieren la utilización de una metodología funcional. Para alcanzarlos, deben ponerse en marcha una metodología participativa.

Cada docente universitario, debe tomar decisiones acerca de su propio mejoramiento; los programas de perfeccionamiento permanente o formación permanente, deben permitir a los docentes universitarios tomar parte en su diseño, realización y evolución.

La característica fundamental de este tipo de metodología es quecada uno de los participantes del programa pasen de una postura decontemplar a tomar parte en la situación de aprendizaje, hasta llegar a ser parte de esa misma situación. 


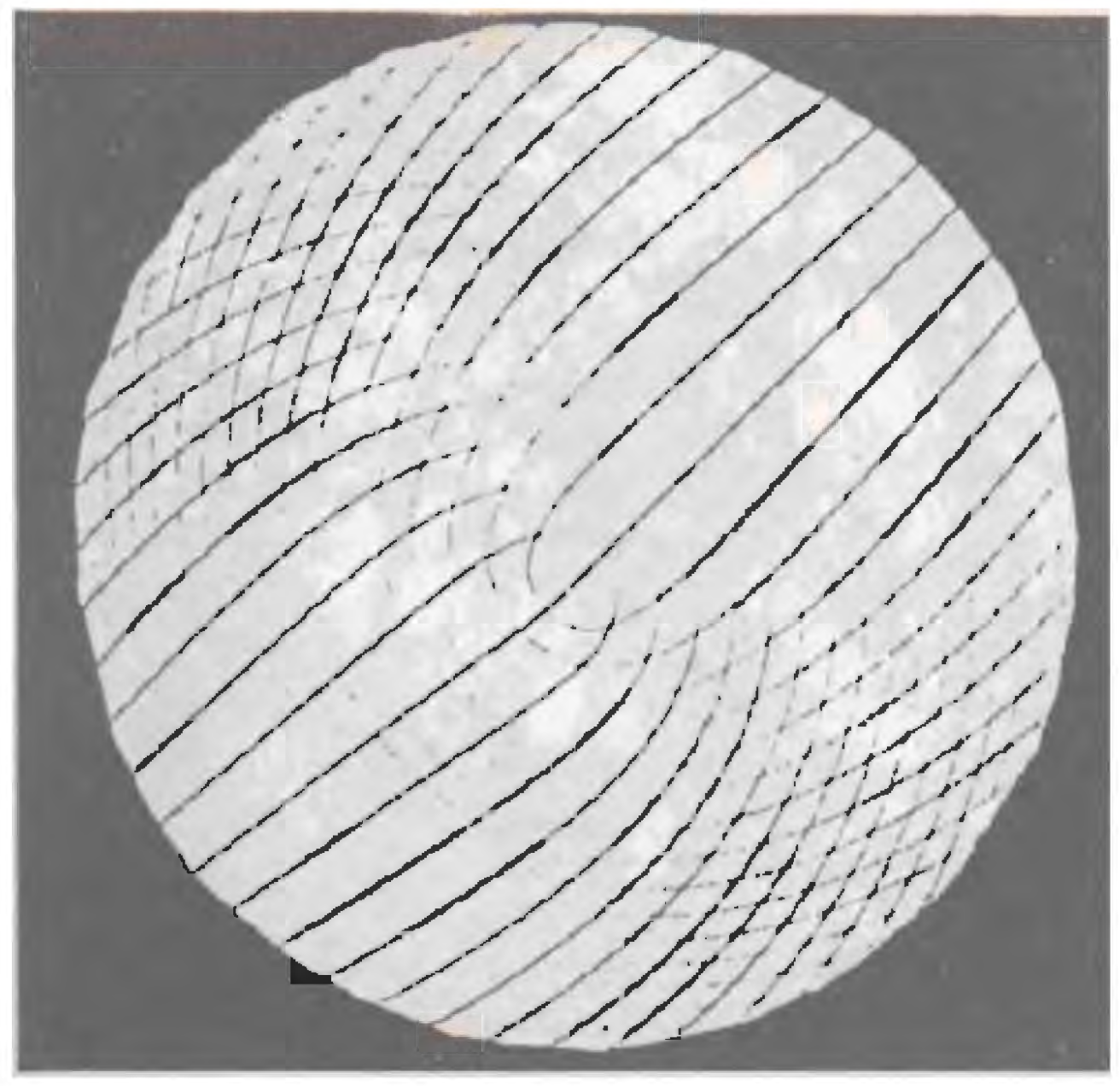

La metodología participativa, tiene como finalidad crear una situación óptima de trabajo para logrardeterminados objetivos de mejora personal. Estas situaciones de trabajo, son en realidad, situaciones de aprendizaje. Incluyen trabajo individual, en muchos casos, trabajos en pequeños grupos y trabajos en grandes grupos.

La metodología participativa, es una combinación de objetivos, de técnicas, de tiempos, de materiales escritos a estudiar, de descansos, de cambios de velocidad en el desarrollo de cada sesión, de flexibilidad, de exigencia, de permisibilidad y de conducción. En consecuencia, esalgo más que una técnica o combinaciones de técnicas.

Toda técnica de aprendizaje, que sirva para conseguir la participación de todos o de la mayor parte de los participantes de un programa intensivo, es una técnica participativa. Habiendo algunas técnicas, por ejemplo, el método del caso, estudio dirigido, etc.
Para que exista realmente participación, debedarse lugarauna mejora; y toda mejora implica un cambio, de lo contrario, no hay participación.

La participación nopuede programarse, pero se requiere una previsión racional de los objetivos y de los pasos a seguir para alcanzarlos. El riesgo está en no lograr esos objetivos por falta de participación. Y por último, existen obstáculos que impiden el logro de una participación de calidad, tales como: falta de costumbre previa, el propio carácter personal, resistencia al cambio, timidez, pesimismo por no ver resultados inmediatos de lo que se está haciendo.

Ahora bien, es necesario recordar que la participación es un proceso y que por lo tanto, no es razonable esperar resultados óptimos al comienzo.

La metodología de participación para los programas de perfeccionamiento, exige las siguientes condiciones:
1. Que la inscripción en los programas de perfecionamiento, responda a una necesidad del docente universitario.

2. Que la implementación del programa, tenga en cuenta las necesidades de cada uno de los participantes.

3. Que el programa se desarrolle, de modo que permita la expresión de tales necesidades.

Las tareas de perfeccionamiento con base en la experiencia personal de quienes componen el grupo de estudio, encuentran en la participación, el cauce adecuado por el cual, con el apoyo de esas experiencias, se relacionen pensamientos y acción.

En los programas intensivos de perfeccionamiento de docentes universitarios, se deben procurar que los mismos docentes queden implicados en la realización del programa, poniendo especial énfasis en la promoción de actitudes de compromiso con la 


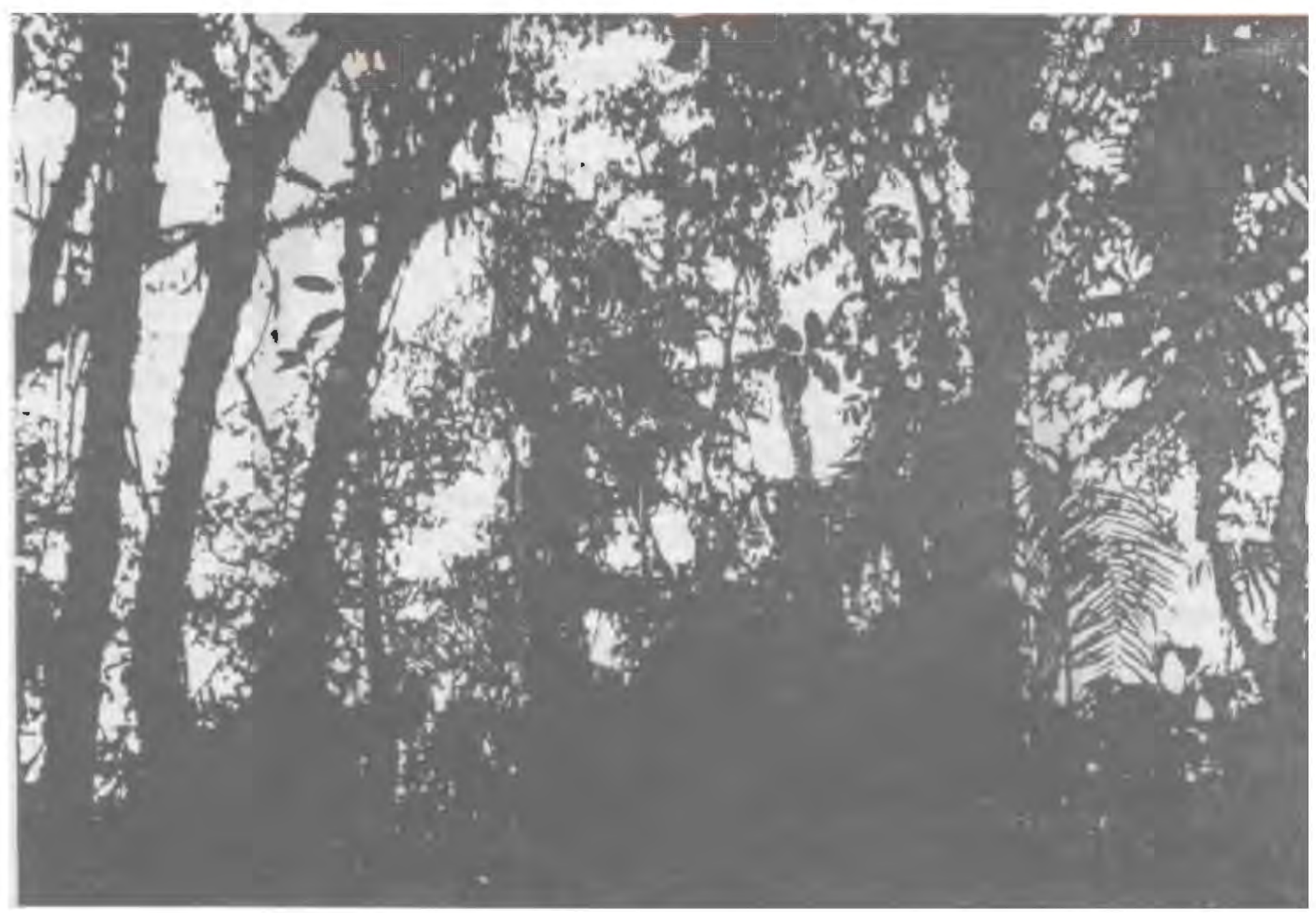

profesión educativa.

\section{B. LA INVESTIGACION DEL DOCENTEUNIVERSITA- RIO}

Derivado de la necesidad de autoperfeccionamiento, aparece la necesidad de que el docente universitario realice investigaciones dentro del quehacer educativo, como medio de dar más vivacidad y eficacia constante a dicha actividad.

Una actuación del docenteuniversitario, como se viene manifestando, dista bastante de ser un trabajo monótono, rutinario, utilizando idéntica metodología, similares procedimientos y motivaciones de año en año.

Ahora bien, nose trata deagregar nuevas cargas a las muchas que ya existen, algunas de ellas innecesarias, sino de hacer bien lo que debe hacer, en creciente toma de conciencia de lo qué se pretende, de cómo realizarlo; de tal manera que el docente uni- versitario, pueda rectificar o reforzar las condiciones de su quehacer educativo.

Investigación, originariamente significa rastreo, seguir una huella. En la vida intelectual, es una actividad que tiene la finalidad de alcanzar nuevos conocimientos o solucionar nuevos problemas. La investigación pedagógica, es el quehacer investigadorque tiene por objeto la educación, en cualquiera de sus manifestaciones; es una tarea esencial para que los hombres vayan haciendo más racional y eficaz su actividad; a la vez se evita la práctica rutinaria del quehacer educativo.

Es necesaria la investigación activa, que debe empezar en la realidad educativa y por consiguiente, se ha de contar con los docentes universitarios. Por otra parte, la norma de actuación tiene que ser probada y contrastada por ellos; por lo tanto, los docentes universitarios deben partici- par en la investigación.

Es así como el trabajo del docenteuniversitario, concretadoen una obra bien hecha, es un eficaz resorte educativo. Pero el trabajo no se agota en el ámbito individualde la persona, sino que tiene proyección del sujeto hacia el mundo exterior. El trabajo conlleva necesariamente trascendencia social.

En esencia, la investigación científica no es sino el acto de poner en acción las exigencias de lo que se conoce como método científico.

El conocimiento científico, debe entenderse como aquella modalidad de saber, apoyado en alguna evidencia, quedifícilmente pueda considerarse como algo infalible o definitivo, sino siempre abierto al enfoque correctivo propio de la ciencia, a la revisioa y crítica.

Para realizar una investiga- 
ción científica, es menester seguir un esquema que lleve desde el planteamiento del problema que se quiere estudiar, hasta su solución.

El proceso de investigación, puede ser definido como un camino que va desdela formulación de una pregunta, hasta la respuesta demostrada o justificada.

La actividad investigadora, como es de conocimiento general, tiene los siguientes pasos:

1. Planteamiento del problema

2. Elaboración de hipótesis

3. Recolección de datos y material

4. Elaboración de datos

5. Conclusiones

6. Informe

De todas estas etapas, la primera es la base o cimiento del edificio. Todo trabajo de investigación trata de contestar a una pregunta. Los problemas que se formulen han de verse como factibles de resolverlos.

Una hipótesis, no es más que respuesta provisional quese da a una cuestión; respuesta que debe ser comprobada mediante la investigación a realizar.

La capacidad del docente universitario, para captar problemas, comienza en una actitud de preocupación, es decir, de dedicación de su atención, reflexión y crítica a su propio trabajo diario en la universidad. Los problemas del docente universitario, se plantean partiendo de sus experiencias vívidas. El problema debe plantearse en términos tan precisos como sea posible, de modo que sea factible afirmar o negar su solución en los términos planteados. La mejor manera de formular el problema, es hacerlo en términos de pregunta o preguntas, de manera que posteriormente pueda darse la correspon-

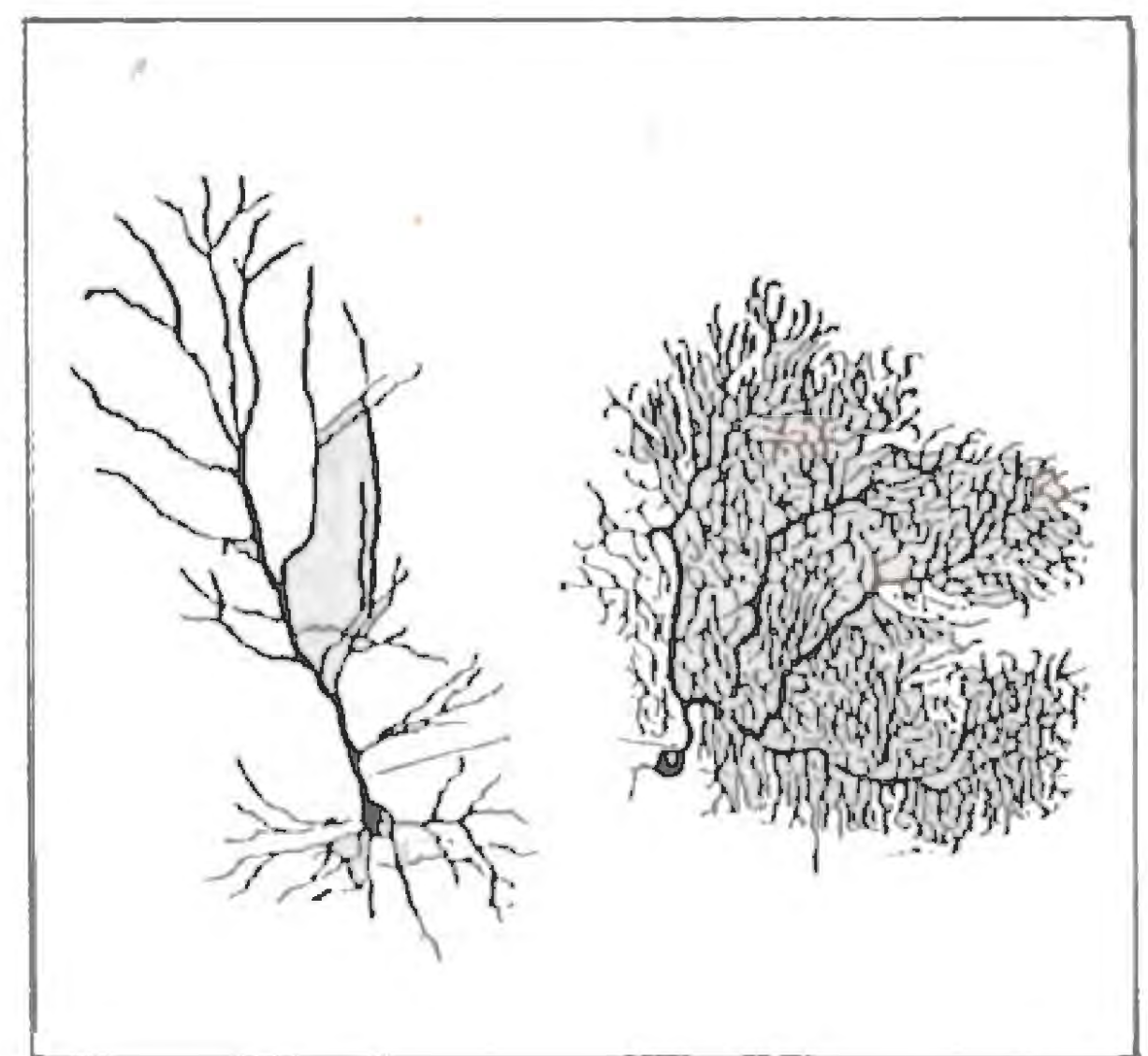

diente contestación.

La realidad educativa, la práctica de la docencia, el marco organizativo, etc., son fuentes de problemas; una actitud lejana a la rutina le hará al docente universitario plantearse un problema y de forma progresiva intentar su solución.

\section{CONCLUSIONES}

Si la educación consiste en el mejoramiento, en el perfeccionamiento intencional y en el crecimiento integral e implica un acción modificadora del hombre sobre el hombre o del hombre sobre sí mismo, debe existir una heteroeducación que conduzca a una autoeducación. Esta definición es aplicable al docente universitario que ya tiene experiencia en el quehacer educativo y al profesional que quiere ejercer la docencia en la universidad.

Una guía efectiva e inteligente del quehacer educativo en el mundo contemporáneo, está en el planteamiento ético del objetivo y de la tarea del educador.

Por consiguiente, además de los conocimientos técnicos, al docente universitario que está inmerso en esta actividad con efi- cacia, debería exigírsele lo siguiente:

\section{VOCACION}

Educar es en todo caso, una auténtica vocación. Se entiende como vocación, la inclinación hacia determinada profesión. Con ella, se logra rendimiento máximo con mínimo esfuerzo y la sociedad obtiene el mayor beneficio.

\section{ADECUADA PERSONA-}

\section{LIDAD}

Es imprescindible esperar de el docente universitario, aptitudes cognocitivas, psicológicas y pedagógicas.

\section{FORMACION BASICA}

Se plantean dos:

a. Moral

Eldocente universitario deberá poseer cualidades morales importantes: paciencia, buen humor, amor a la verdad y alegría. Pero estas exigencias deberán ser completadas y potenciadas con una formación ética intelectual, necesaria para el ejercicio de la docencia.

\section{b. Pedagógica}

Comprenderá cursos que deberían abarcar fundamentalmente: 
- Principios de pedagogía:

* Psicología educativa

* Sociología educativa

* Filosofía educativa

- Principios de didáctica general - Principios de didáctica especial

Estos conocimientos deberán ser integrados por un período de prácticas supervisadas.

Si toda actividad humana, tiene sus métodos específicos para alcanzar sus fines, un elemento clave y primario de la formación del docente universitario, es el estudio de los métodos. El método pedagógico, es la manera de dirigir, guiar y estimular a los educandos en el proceso de aprendizaje.

En síntesis, la vocación da las aptitudes necesarias para el ejercicio de la docencia universitaria, pero no bastan. La misma vocación, conlleva la necesidad de una formación básica inicial para el ejercicio de la profesión docente.

Además, en tiempos actuales, se está asistiendo a una constante profesionalización de la tarea educativa y a rápidos cambios en la ciencia y en la sociedad, que exigen la necesidad de un continuo reciclaje o readaptación educativa, es decir, a una formación permanente. No basta una formación inicial. El profesional de la educación se está haciendocontinuamente.

$\mathrm{Al}$ respecto, se proponen dos formas fundamentales de lograr la formación pedagógica permanente:

- Los programas intensivos con metodología participativa.

- La investigación del docente universitario

El verdadero educador, siempre está en camino, nunca llegará el día en que pueda considerarse plenamente satisfecho de sí mismo. Siempre deberá existir en él, la ilusión profesional que lo lleve a un anhelo de perfeccionamiento $\mathrm{y}$ autoperfeccionamiento permanente.

Teniendo en cuenta las diferencias que existen entre enseñar y educar, se puede distinguir la figura del simple docente-instructor, del docente-educador.

Los docentes-educadores, deben alentar la comunicación con sus alumnos, usando como medio la enseñanza de su materia y de su propia actitud, tratando de despertar capacidades latentes y formándolos intelectualmente y humanamente.

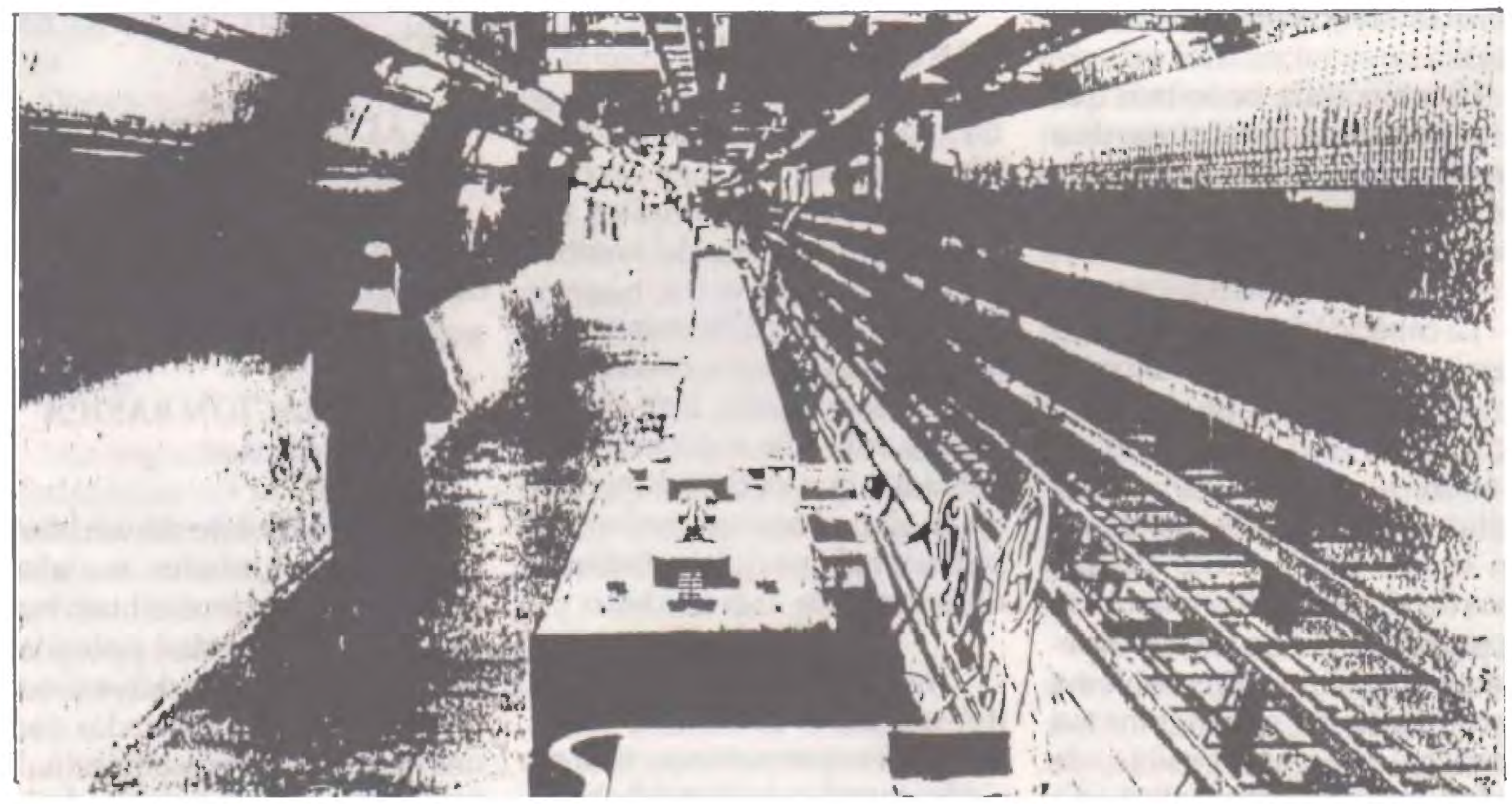

